- ACORN Australan college of | JOURNAL OF PERIOPERATIVE NURSING

\title{
Preventing perioperative hypothermia is clinically feasible and cost effective
}

Follow this and additional works at: https://www.journal.acorn.org.au/jpn

Part of the Health Services Administration Commons, Health Services Research Commons, Perioperative, Operating Room and Surgical Nursing Commons, and the Surgery Commons

(c) (†)

This work is licensed under a Creative Commons Attribution 4.0 License.

\section{Recommended Citation}

Ralph, Nicholas (2019) "Preventing perioperative hypothermia is clinically feasible and cost effective," Journal of Perioperative Nursing: Vol. 32 : Iss. 1 , Article 1.

Available at: https://doi.org/10.26550/2209-1092.1051

https://www.journal.acorn.org.au/jpn/vol32/iss1/1

This Article is brought to you for free and open access by Journal of Perioperative Nursing. It has been accepted for inclusion in Journal of Perioperative Nursing by an authorized editor of Journal of Perioperative Nursing. 


\section{ACORN}

The Australian College of Perioperative Nurses (ACORN) is a registered Australian company and health promotion charity. It exists to serve its members, the perioperative profession, the patient and the community to promote the prevention and control of disease.

ACORN's vision is for Australian patients to receive the safest and highest quality evidence-based perioperative care in the world.

\section{ACORN Board of Directors}

Rebecca East

President

Trent Batchelor

Director

\section{Patricia Flood}

Director

Journal Committee Chair and Research

Committee Chair

\section{Karen Hay}

Director

Conference Committee Chair and Professional advocacy and advisory

liaison

\section{Grace Loh}

Director

Hospital and University Collaboration and Accreditation Committee Chair

Grants, Awards and Scholarships Committee Chair

Paula Foran

Member Director

Membership and Local Associations Liaison Committee Chair

Sophie Ehrlich

Director

Education Programs Committee Chair

Donna Stevens

Director

Education Committee Chair

\section{Garry Stratton}

Director

Finance, Audit and Risk Committee Chair

\section{Editorial}

\section{Preventing perioperative hypothermia is clinically feasible and cost effective}

Inadvertent perioperative hypothermia is associated with serious adverse surgical outcomes including increased infection rates, morbid cardiac events and surgical bleeding. Surgical patients are particularly at risk of hypothermia because of 'anaesthetic-induced impairment of thermoregulatory control' and the 'cool operating room' temperature that create the perfect combination for developing hypothermia post-surgery ${ }^{1,2}$.

Perioperative hypothermia develops in three characteristic phases:

1. a rapid decrease in core temperature in the first hour due to core to peripheral redistribution of body heat mediated by the use of volatile anaesthetic agents

2. a slow linear decrease in core temperature due to heat loss exceeding metabolic heat gain

3. a plateau in temperature in which vasoconstriction decreases heat loss from the skin ${ }^{3}$.

Perioperative hypothermia increases the incidence of complications following surgery. Reducing the incidence of perioperative hypothermia through appropriate perioperative care can reduce the number and complexity of complications that arise. Sessler ${ }^{2}$ investigated the complications that arise from hypothermia by reviewing the current literature and reported a dozen major health consequences. Myocardial ischemia, coagulopathy or
Associate Professor Nicholas Ralph PhD, MClinPrac (Perioperative Nursing), RN School of Nursing \& Midwifery, University of Southern Queensland

Jeffrey Gow

$\mathrm{PhD}, \mathrm{MEcon}$

School of Commerce, University of Southern Queensland

\section{Jed Duff}

PhD, BN

School of Nursing and Midwifery, University of Newcastle

blood loss, prolonged hospitalisation and thermal discomfort are just a few examples of the serious complications that are caused by perioperative hypothermia. Enzymes that regulate organ functions and process medications, for instance, are very sensitive to the change in body temperature and consequently hypothermia affects the pharmacodynamics of many drugs.

\section{Recent developments in thermal care}

The United Kingdom National Institute for Health and Clinical Excellence (NICE) has published a guideline 'Perioperative hypothermia (inadvertent): The management of inadvertent perioperative hypothermia in adults' detailing appropriate perioperative thermal management to minimise the occurrence of perioperative hypothermia. The guideline is based on a comprehensive systematic review including both meta-analysis and cost-effectiveness analysis ${ }^{4}$.

Recommendations from the guideline include the requirement for preoperative hypothermia risk assessment, regular temperature monitoring, and active and passive warming strategies. However, compliance with recommendations in clinical practice is poor despite their relative simplicity and costeffectiveness. For example, results from a large European multisite 
observational study $(\mathrm{n}=8083)$ conducted prior to the NICE guideline development found that temperature monitoring was not appropriately undertaken in 81 per cent of patients ${ }^{5}$. Both the Australian and New Zealand College of Anaesthetists and the Royal Australasian College of Surgeons clinical guidelines reflect the recommendations of the NICE guideline ${ }^{3}$.

In 2014 a thermal care bundle was developed by a panel of Australian expert clinicians and researchers to improve the prevention, detection and treatment of perioperative hypothermia in adult surgical patients ${ }^{6,7}$. Implementing a thermal care bundle can help rapidly disseminate optimal clinical guidelines for the management of health care-associated illnesses and risks. The bundle elements were selected from the NICE guideline on the management of perioperative hypothermia in adults.

\section{Economics of preventing perioperative hypothermia}

In a report soon to be released, the authors will provide a detailed economic analysis on the costeffectiveness of preventing inadvertent perioperative hypothermia in Australia. Using rigorous up-to-date data, the authors report findings based on a scenario of 80 per cent compliance with guidelines effective for reducing perioperative hypothermia. They found that the total cost of perioperative hypothermia to the Australian health system is \$1.26 billion and that preventing perioperative hypothermia has an annual net benefit of:

- \$602 million to the Australian health system

- approximately $\$ 7085$ per patient for major surgery (with an overnight stay) from reducing SSIs alone

- approximately $\$ 6560$ per patient for minor surgery (with an overnight stay) from reducing SSIs alone.

This report is of significance to all perioperative nurses in Australia as the prevention of hypothermia is often led by nurses and denotes the value of high reliability nursing care. Significantly, the authors recommend that:

- current best practice is adopted ensuring that thermal care is provided to 'every patient, every time'

- a national multidisciplinary-based policy for preventing and managing perioperative hypothermia is developed

- a definitive clinical trial on perioperative hypothermia is conducted.
With the release of this report expected in the first half of 2019, we encourage all perioperative nurses to take heart in recognising the significant value they provide to the Australian health care system by delivering excellent perioperative care.

\section{References}

1. Sessler D. Perioperative thermoregulation and heat balance. Lancet 2016;387(10038):2655-2664.

2. Sessler D. Complications and treatment of mild hypothermia. Anesthesiology 2001;95(2):531-543.

3. Australian and New Zealand College of Anesthetists (ANZCA). Perioperative normothermia: Clinical audit guide. ANZCA: Sydney, 2013.

4. National Collaborating Centre for Nursing and Supportive Care. The management of inadvertent perioperative hypothermia in adults: Prevention and management in adults. Clinical practice guideline. NICE: London, 2008

5. Torossian A. Survey on intra-operative temperature management in Europe. Eur J Anaesthesiol 2007;24(8):668-675.

6. Duff J, Walker K, Edward K, Williams $R$, Sutherland-Fraser S. Incidence of perioperative inadvertent hypothermia and compliance with evidence-based recommendations at four Australian hospitals: A retrospective chart audit. Journal of Perioperative Nursing 2014;27(3):16-23.

7. Duff J, Walker K, Edward K, Ralph N, Giandinoto J, Alexander K, Gow J, Stephenson J. Effect of a thermal care bundle on the prevention, detection and treatment of perioperative inadvertent hypothermia. J Clin Nurs 2018;27(5-6):1239-1249. 